Allergy News

\section{Unnötige Katzenwäsche}

$\mathrm{K}$ atzenallergiker weigern sich manchmal hartnäckig, ihr geliebtes Haustier abzuschaffen. Die dann gern gegebene Empfehlung, das Tier regelmäßig $\mathrm{zu}$ waschen, ist aber nicht geeignet, die Allergenmenge dauerhaft zu reduzieren. In einer Studie mit zwölf Katzen fiel zwar die abgesonderte Allergenmenge nach einer Waschprozedur mit zweimal dreiminütigem Eintauchen der Tiere bis zum Hals kurzfristig ab, war aber im Durchschnitt nach vier Stunden wieder auf dem Ausgangsniveau. Das Hauptallergen Fel d 1 wird offenbar innerhalb kurzer

\section{Schimmel schadet immer}

D ie Familie hatte sich so sehr auf ihr neues Häuschen gefreut. Dann der Schock: Der Dachstuhl, gerade erst eingebaut, war verschimmelt! Der Familienvater schrieb daraufhin an den Architekten einen gesalzenen Brief: Schimmelpilze seien Schadstoffe, die krank machen, Architekt und Baufirma müssten diesen offensichtlichen Mangel beseitigen. Der Architekt schlug vor, den Dachstuhl sanieren zu lassen. Dass danach noch Pilzsporen in Wohnräume gerieten, sei unwahrscheinlich - ein geringes Restrisiko sei aber nicht völlig auszuschließen. Diesen Vorschlag akzeptierte der Bauherr

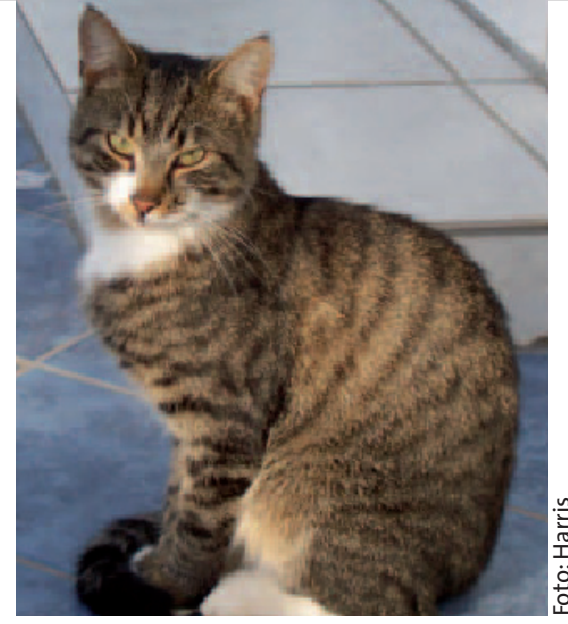

Zeit in klinisch relevanten Mengen nachproduziert

$b k$

Nageotte C et al. J Allergy Clin Immunol 2006; 118: 521-2 nicht, er ließ stattdessen den kompletten Dachstuhl auswechseln. Die Kosten sollte die Baufirma übernehmen, die das marode Gehölz eingebaut hatte. Zunächst scheiterte der Häuslebauer mit seiner Klage: Er hätte das Sanierungsangebot annehmen müssen, fand das Landgericht. Der Bauherr habe einen einwandfreien Dachstuhl bestellt, urteilte dagegen der Bundesgerichtshof, den müsse die Baufirma also auch liefern. Eine Sanierung, die lediglich das Risiko für die Gesundheit verringere, genüge nicht.

gri

Bundesgerichtshof, VII ZR 274/O4

\title{
Warten auf den nächsten Kuss
}

E rdnussallergiker sind nicht nur durch versteckte Allergene in der Nahrung, sondern auch durch zufälligen Kontakt mit Allergen in der Umgebung gefährdet. Das spielt beispielsweise dann eine Rolle, wenn der Allergiekranke seinen Partner nach dem Knabbern von Erdnüssen küssen will. Wie lange sich Erdnussallergene im Speichel halten, haben US-Forscher jetzt mit Freiwilligen untersucht: Eine Wartezeit von einigen Stunden und das Essen einer erdnussfreien Mahlzeit sind die effektivsten Methoden, um die Erdnussallergene im Speichel zu eliminie-

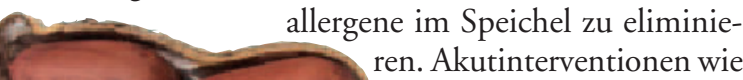
Zähneputzen, Mundspülungen und Kaugummikauen reduzieren zwar ebenfalls die Ara-h-1Spiegel - jedoch nicht unter eine möglicherweise noch klinisch relevante Konzentration.

$b k$

Maloney JM et al. J Allergy Clin Immunol 2006; 118: 719-24

\section{Blauer Schweiß}

D as Antibiotikum Minocyclin wird seit vielen Jahren zur Behandlung von Acne vulgaris eingesetzt. Seltene Nebenwirkungen sind Lupus-erythematodesähnliche Syndrome und Autoimmunhepatitis, gut bekannt sind Verfärbungen verschiedener Körpergewebe, beispielsweise von Nägeln, Knochen, Zähnen, Konjunktiven und sogar der Schilddrüse. Ein Fallbericht aus Großbritannien ergänzt die Liste: Eine 44-Jährige mit schwerer Akne sonderte nach Minocyclin-Einnahme bläulichen Schweiß ab - allerdings nur in der Nacht und nur prämenstruell. Nach Absetzen der Medikation verschwand das Symptom, nach einer Erklärung wird noch gesucht.

Hussain W et al. J Eur Acad Dermatol Venereol 2006; 20:763

\section{Medizin-Weltmeister}

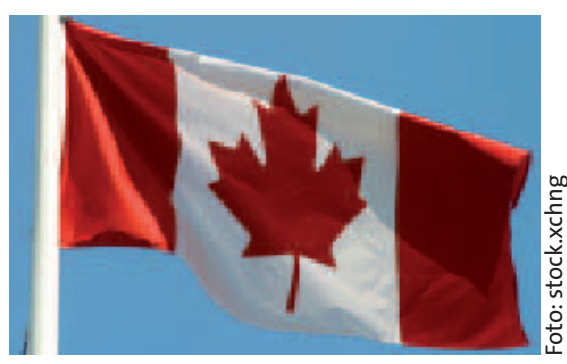

riechische Forscher wollten wissen, welches Land den größten Beitrag zur medizinischen Forschung erbringt. Dazu summierten sie die Anzahl der in den Jahren 1995 bis 2003 publizierten Arbeiten unter Berücksichtigung des Impact-Faktors der jeweiligen Zeitschrift auf. Absolut gesehen steht Westeuropa in den Bereichen Infektionskrankheiten und Herz-Kreislauf-Krankheiten mit 39\% bzw. 40\% Forschungsanteil an der Spitze. Die USA führen dagegen bei Präventivmedizin, Public Health und Epidemiologie. Bei der Auswertung für einzelne Staaten und korrigiert für Einwohnerzahl und Bruttosozialprodukt ergab sich dann aber ein überraschender Medizin-Weltmeister: Kanada.

es

Falagas ME et al. CMAJ 2006; 175: 1389-90 